\title{
Teknologi Virtual Reality dalam Arsitektur sebagai Bentuk Penanganan Stres Masyarakat Perkotaan pada Masa Kini
}

\author{
Stephanie Febrianti Hidayat dan Josef Prijotomo \\ Departemen Arsitektur, Fakultas Teknik Sipil dan Perencanaan, Institut Teknologi Sepuluh Nopember (ITS) \\ e-mail: embah.petungan@gmail.com
}

\begin{abstract}
Abstrak-Seiring dengan perkembangan zaman, kehidupan masyarakat, khususnya masyarakat perkotaan, seringkali menuntut mereka untuk mampu mengerjakan banyak hal dalam suatu waktu yang menyebabkan masyarakat rentan mengalami tekanan pikiran dalam hidupnya. Tekanan ikiran yang berkepanjangan akan menimbulkan stres yang berdampak kepada penurunan kinerja seseorang. Oleh sebab itu, diperlukan suatu kehadiran arsitektur sebagai buah pikiran manusia yang ideal, sehingga mampu mewadahi kegiatan penanganan stres yang sesuai dengan kondisi perkotaan masa kini. Layaknya buah pikiran, maka arsitektur hendaknya juga mampu mencitrakan pikiran yang sehat kepada manusia. Hal ini dilakukan untuk menyadarkan manusia bahwa sebenarnya kunci pengendalian pikiran mereka agar tidak rentan stres ialah dengan menyadari dan mengenali pikiran mereka sendiri. Dengan menggunakan bantuan teknologi masa kini, arsitektur, selain hendak diwujudkan sebagai bentuk inovasi didalam kegiatan merancang, juga hendak diwujudkan sebagai citra pikiran seseorang sesungguhnya yang bersifat tanpa batas.
\end{abstract}

Kata Kunci-Arsitektur, Perkotaan, Pikiran, Teknologi.

\section{PENDAHULUAN}

$\mathrm{M}$ ASALAH yang dihadapi oleh perkotaan sejatinya sangat banyak, misalnya keterbatasan lahan, dan kurangnya suasana alam yang mampu memberikan ruang bagi masyarakat untuk menenangkan diri sejenak dari rutinitas mereka.

Seiring dengan perkembangan zaman, maka teknologi pun turut berperan dengan signifikan mempengaruhi aspek kehidupan manusia. Teknologi ini diharapkan mampu menyelesaikan permasalahan keterbatasan ini, dan menjawab solusi atas keterbatasan akan kebutuhan personal didalam berkontemplasi untuk mengenal pikirannya sendiri dan melakukan pengelolaan pikiran sehingga tidak rentan mengalami tekanan pikiran sehingga lebih mampu mengontrol stres.

Melihat potensi teknologi masa kini, maka hal ini dapat dimanfaatkan untuk menciptakan ruang bagi perorangan untuk melakukan perenungan atau meditasi untuk mengenal dan memahami pikiran masing-masing sebelum kemudian mengatasi rasa stres masing-masing, dengan tingkat privasi yang tinggi (Gambar. 1). Dengan bantuan para ahli didalam penanganan stres, maka arsitektur dapat dihadirkan sebagai citra pikiran manusia, dimana manusia pengguna seolah-olah seperti sedang berinteraksi dengan pikirannya dan mengenal citra pikiran yang sehat dan stabil.
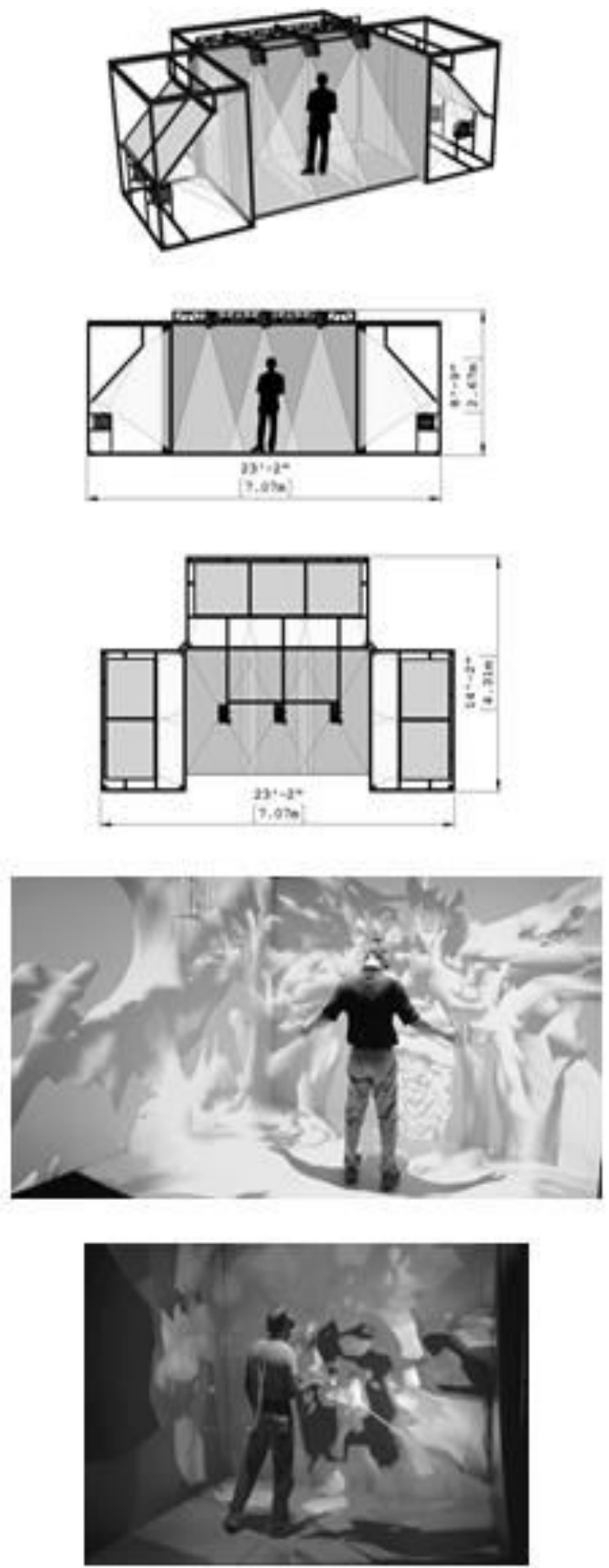

Gambar. 1. Ruang simulasi teknologi Virtual Reality [1] 
Saat ini, teknologi Virtual Reality (VR) telah berkembang pesat, sehingga hampir dianggap mampu menciptakan suasana sama seperti aslinya tanpa perlu mengunjungi tempat secara langsung. Teknologi Virtual Reality (VR) juga sangat efektif didalam mendistraksi manusia [2]. Hal ini terbukti dari penggunaan gadget yang telah dianggap sebagai kebutuhan vital bagi sebagian orang. Apabila ponsel pintar saja cukup untuk mendistraksi manusia, maka teknologi $V R$ dapat dipastikan akan sangat mampu membuat manusia melupakan sekitarnya, dalam hal ini perasaan tertekan dalam pikiran, dan fokus kepada pengendalian pikiran untuk menanggulangi stres.

\section{METODE RANCANG}

Berdasarkan proses pengenalan seseorang terhadap arsitektur sebagai citra pikirannya sendiri, maka diperlukan metode yang dapat mengabstraksikan pola interaksi antara arsitektur dengan manusia. Agar manusia dapat merasakan ketenangan jiwa dalam arsitektur selama proses terapi pengendalian pikiran. Metode yang dipilih adalah metode Narrative.

Narrative merupakan metode desain yang menggunakan proses kreatif didalam mendesain arsitektur berdasarkan serangkaian cerita yang berurutan untuk mencapai tujuan didalam perancangan sebuah arsitektur [3].

Metode Desain Narrative akan diterapkan dalam desain sebagai serangkaian urutan cerita tentang proses perkenalan, mulai dari mengamati hingga mengenal arsitektur sebagai citra pikiran yang stabil (Gambar. 2). Dengan demikian apabila para pengunjung menghadapi tekanan hidup di kemudian hari, mereka akan berusaha mengendalikan kesadaran mereka dan mengontrol tekanan tersebut sebagaimana pengalaman mereka ketika melakukan proses terapi melalui tahapan-tahapan pengenalan terhadap arsitektur ini.

\section{A. Tahap Pengamatan}

Merupakan tahapan paling awal didalam proses perkenalan. Didalam proses pengamatan, seseorang akan menggunakan inderanya untuk memutuskan apakah ia akan tertarik untuk memulai perkenalan.

\section{B. Tahap Salam Pembuka}

Merupakan tahapan selanjutnya saat pengunjung sudah masuk kedalam bangunan. Tahapan ini berupa ruang transisi yang seolah "memisahkan" pengunjung dengan sekitarnya yang membuatnya mengalami perasaan tertekan, sehingga pengunjung akan merasa lebih rileks.

\section{Tahap Penyambutan}

Setelah melewati ruang transisi, pengunjung akan tiba di ruangan yang didesain sesuai untuk merilekskan pandangan dan pikiran dan membiasakan diri sebelum memulai proses terapi penanganan stres dengan $V R$.

\section{Tahap Percakapan}

Merupakan tahapan praktik terapi penanganan stres yang berbentuk interaksi dua arah antara pengunjung dengan pikirannya melalui bantuan kotak $V R$. Kotak $V R$ ini digunakan untuk memfasilitasi keterbatasan tempat pada perkotaan dengan cara yang efektif. Sehingga pengunjung dapat menentukan suasana terapi apa yang sesuai untuknya dengan bantuan para ahli penanganan stres, tanpa perlu bepergian jauh untuk mencari tempat yang sesuai.

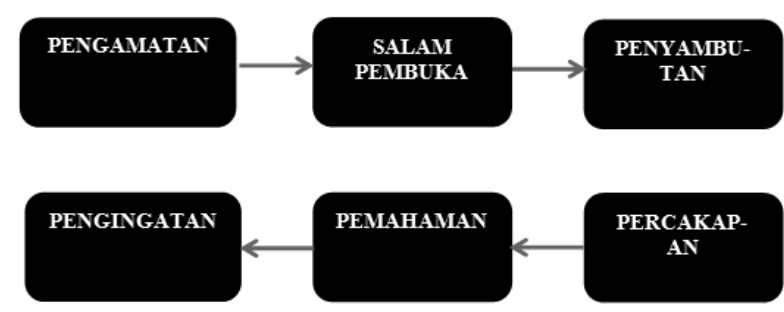

Gambar. 2. Diagram alur narasi desain
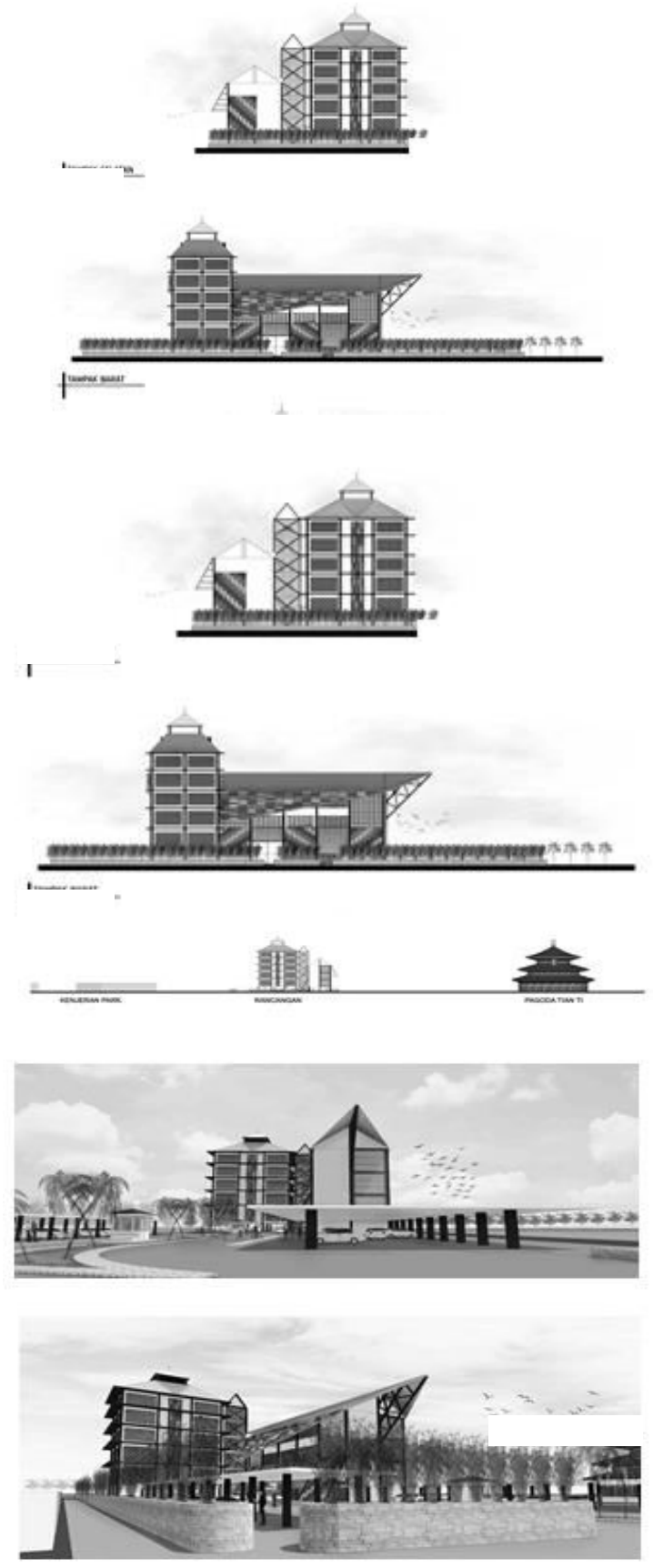

Gambar. 3. Kontras tampilan bangunan 


\section{E. Tahap Pemahaman}

Apabila tahap Percakapan berjalan dengan baik, maka pengunjung akan merasakan efek rileks yang membuat mereka berpikir jernih sehingga mereka akan mulai merefleksikan masalah masing-masing dan hal-hal apa yang menyebabkan mereka menjadi tertekan.

\section{F. Tahap Pengingatan}

Dalam proses pengingatan ini, arsitektur tidak lagi berperan dalam berinteraksi dengan manusia, melainkan manusia yang akan mengingat arsitektur berdasarkan pengalaman kualitas tahapan "perkenalannya" dengan arsitektur

\section{HASIL DAN EKSPLORASI}

\section{A. Pengamatan $=$ Kontras Tampilan Bangunan. $($ Gambar. 3$)$}

Sebelum memasuki tapak, pengunjung akan dihadapkan kepada sosok bangunan yang menandakan lokasinya. Oleh karena indera penglihatan sangat mudah mengenali kekontrasan, maka selubung bangunan akan didesain kontras dengan sekitarnya.

\section{B. Salam Pembuka $=$ Lorong Interaktif (Gambar. 4)}

Yang berperan memisahkan pengunjung dari suasana perkotaan untuk memasuki suasana baru didalam citra pikiran arsitektur. Pada lorong akan dijumpai suasana yang baru dan dengan menggunakan material-material alami yang kontras dengan material perkerasan yang umumnya dijumpai pada bangunan-bangunan di perkotaan.

\section{Penyambutan = Lobi dan Area Duduk (Gambar. 5)}

Setelah melewati lorong interaktif, di ujung lorong tersebut pengunjung akan menemui cahaya yang akan mengantarkan mereka ke lobi dan mengurus administrasi terlebih dahulu.

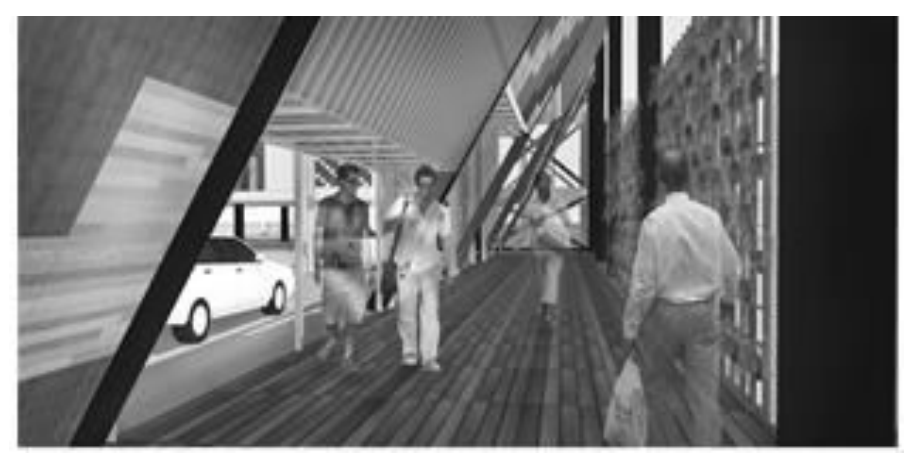

Gambar. 4. Perspektif lorong interaktif.

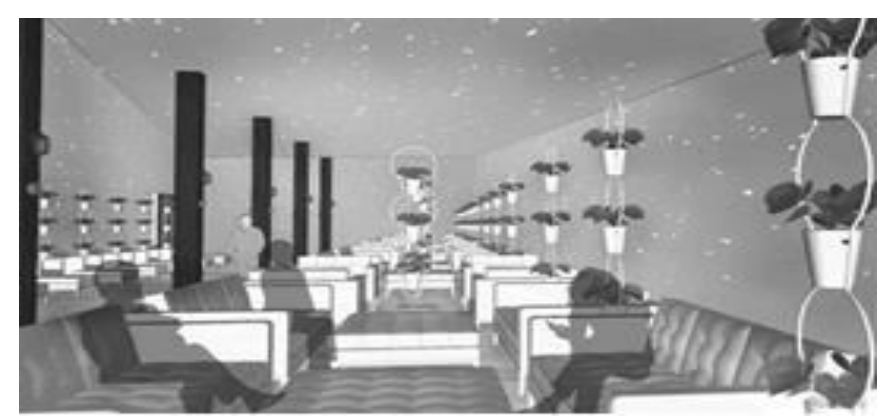

Gambar. 5. Perspektif lobi dan area duduk

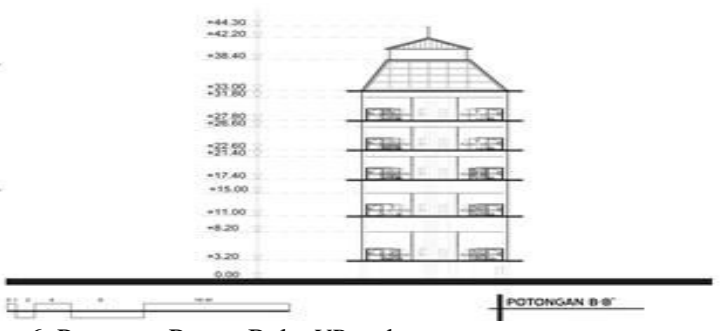

Gambar. 6. Potongan Ruang Boks $V R$ pada rancangan

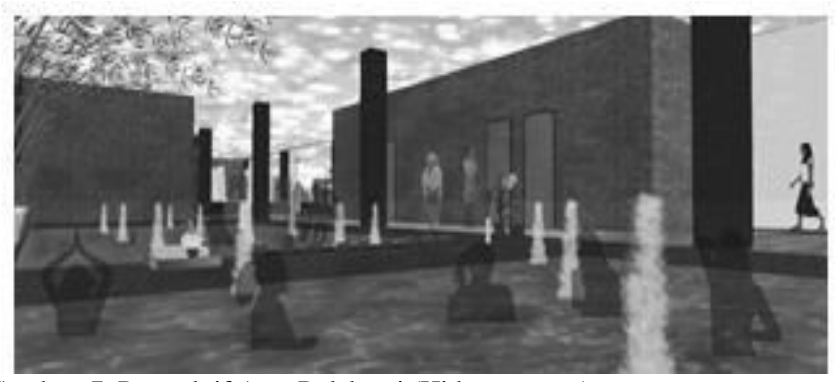

Gambar. 7. Perspektif Area Relaksasi (Hidromassage).

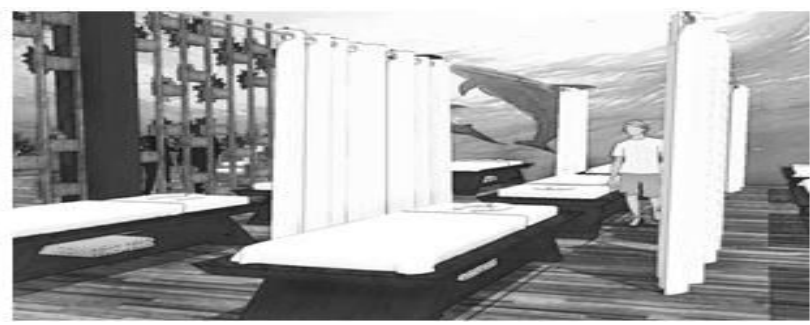

Gambar. 8. Perspektif Area Relaksasi (Area massage).

\section{D. $\quad$ Percakapan $=$ Boks Virtual Reality $($ VR $)($ Gambar. 6)}

Boks Virtual Reality (VR) menyerupai ruang dimana pengguna dapat mengendalikan simulasi yang dimainkan dengan bebas dengan pointer, sehingga mereka dapat seolah berjalan-jalan di taman, pantai, salju, dll. selama mereka memakai kacamata $V R$.

\section{E. Pemahaman $=$ Area Relaksasi $($ Gambar. 7 dan Gambar . 8)}

Suatu ruang yang mampu mendukung aktivitas ini dengan stimulasi indera yang memiliki dampak menenangkan dengan Projector yang dapat diatur sesuai dengan keinginan pengunjung untuk mendukung suasana sehingga mampu meningkatkan konsentrasi mereka didalam tahap kontemplasi berupa pengendalikan kesadaran dan menemukan cara untuk mengatasi tekanan dalam pikiran.

\section{KESIMPULAN}

Arsitektur sebagai buah pikiran manusia dapat dirancang agar ia juga berfungsi sebagai pemulih dari pikiran manusia lain yang tertekan. Peran arsitektur sebagai fasilitas terapi penanganan stres masyarakat perkotaan masa kini mampu mewadahi citra pikiran manusia yang baik untuk "ditularkan" kepada orang lain memiliki tekanan pikiran, sehinga mereka menjadi lebih memahami dan mengenal pikiran mereka sendiri yang kemudian mampu menangkal stres tersebut. 
Arsitektur tidak juga diciptakan sebatas penyalur pikiran kepada orang lain dan membantu orang lain merefleksikan jalan pikirannya, namun arsitektur juga memiliki serangkaian kisah didalamnya dan ia haruslah berkembang sesuai dengan zamannya, sehingga ia tetap mencitrakan keadaan masyarakat pada suatu masa.

\section{DAFTAR PUSTAKA}

[1] Visbox.Inc, "Visbox brochure."

[2] H. R. Dirk Donath, "Using Immersive Virtual Reality Systems for Spatial Designing Architecture."

[3] C. Ouyang, "Narrative in design process," 2012. 